\title{
Mixed-methods economic evaluation of the implementation of tobacco treatment programs in National Cancer Institute- designated cancer centers
}

Ramzi G. Salloum ${ }^{1 *}$ D, Heather D'Angelo², Ryan P. Theis ${ }^{1}$, Betsy Rolland ${ }^{2,3}$, Sarah Hohl², Danielle Pauk², Jennifer H. LeLaurin', Yasmin Asvat', Li-Shiun Chen ${ }^{5}$, Andrew T. Day ${ }^{6}$, Adam O. Goldstein ${ }^{7}$, Brian Hitsman ${ }^{8}$, Deborah Hudson ${ }^{9}$, Andrea C. King ${ }^{10}$, Cho Y. Lam" ${ }^{11}$, Katie Lenhoff ${ }^{12}$, Arnold H. Levinson ${ }^{13}$, Judith Prochaska ${ }^{14}$, Fabrice Smieliauskas ${ }^{15}$, Kathryn Taylor ${ }^{16}$, Janet Thomas ${ }^{17}$, Hilary Tindle ${ }^{18}$, Elisa Tong ${ }^{19}$, Justin S. White ${ }^{20}$, W. Bruce Vogel ${ }^{1}$, Graham W. Warren ${ }^{21}$ and Michael Fiore ${ }^{2,3,22}$

\begin{abstract}
Background: The Cancer Center Cessation Initiative (C3I) was launched in 2017 as a part of the NCl Cancer Moonshot program to assist $\mathrm{NCl}$-designated cancer centers in developing tobacco treatment programs for oncology patients. Participating centers have implemented varied evidence-based programs that fit their institutional resources and needs, offering a wide range of services including in-person and telephone-based counseling, point of care, interactive voice response systems, referral to the quitline, text- and web-based services, and medications.
\end{abstract}

Methods: We used a mixed methods comparative case study design to evaluate system-level implementation costs across 15 C3I-funded cancer centers that reported for at least one 6-month period between July 2018 and June 2020. We analyzed operating costs by resource category (e.g., personnel, medications) concurrently with transcripts from semi-structured key-informant interviews conducted during site visits. Personnel salary costs were estimated using Bureau of Labor Statistics wage data adjusted for area and occupation, and non-wage benefits. Qualitative findings provided additional information on intangible resources and contextual factors related to implementation costs.

(Continued on next page)

\footnotetext{
* Correspondence: rsalloum@ufl.edu

${ }^{1}$ Department of Health Outcomes and Biomedical Informatics, University of Florida College of Medicine, 2004 Mowry Road, Gainesville, FL, USA

Full list of author information is available at the end of the article
}

(c) The Author(s). 2021 Open Access This article is licensed under a Creative Commons Attribution 4.0 International License, which permits use, sharing, adaptation, distribution and reproduction in any medium or format, as long as you give appropriate credit to the original author(s) and the source, provide a link to the Creative Commons licence, and indicate if changes were made. The images or other third party material in this article are included in the article's Creative Commons licence, unless indicated otherwise in a credit line to the material. If material is not included in the article's Creative Commons licence and your intended use is not permitted by statutory regulation or exceeds the permitted use, you will need to obtain permission directly from the copyright holder. To view a copy of this licence, visit http://creativecommons.org/licenses/by/4.0/. The Creative Commons Public Domain Dedication waiver (http://creativecommons.org/publicdomain/zero/1.0/) applies to the data made available in this article, unless otherwise stated in a credit line to the data. 
(Continued from previous page)

Results: Median total monthly operating costs across funded centers were $\$ 11,045$ (range: $\$ 5129-\$ 20,751$ ). The largest median operating cost category was personnel $(\$ 10,307$; range: $\$ 4122-\$ 19,794)$, with the highest personnel costs attributable to the provision of in-person program services. Monthly (non-zero) cost ranges for other categories were medications (\$17-\$573), materials (\$6-\$435), training (\$96-\$516), technology $(\$ 171-\$ 2759)$, and equipment (\$10-\$620). Median cost-per-participant was $\$ 466$ (range: \$70-\$2093) and cost-per-quit was $\$ 2688$ (range: \$330-\$9628), with sites offering different combinations of program components, ranging from individuallydelivered in-person counseling only to one program that offered all components. Site interviews provided context for understanding variations in program components and their cost implications.

Conclusions: Among most centers that have progressed in tobacco treatment program implementation, cost-perquit was modest relative to other prevention interventions. Although select centers have achieved similar average costs by offering program components of various levels of intensity, they have varied widely in program reach and effectiveness. Evaluating implementation costs of such programs alongside reach and effectiveness is necessary to provide decision makers in oncology settings with the important additional information needed to optimize resource allocation when establishing tobacco treatment programs.

Keywords: Implementation costs, Economic evaluation, Mixed methods, Smoking cessation, Tobacco treatment

\section{Contributions to the literature}

- Economic evidence from cancer care extends the broad evidence base that tobacco treatment programs provide good value compared with other healthcare interventions.

- This study contributes to our limited understanding of the resources required to implementation tobacco treatment programs in cancer care settings and the economic implications of various program designs by examining the costs of tobacco treatment programs at cancer centers participating in the Cancer Center Cessation Initiative.

- Using a mixed methods, comparative case study design, the study finds that cost-per-quit is modest relative to other prevention interventions, regardless of tobacco treatment program design.

\section{Background}

More than one in six cancer survivors in the United States is a current tobacco user [1]. Continued tobacco use by cancer patients is associated with multiple adverse outcomes including increased overall and cancerspecific mortality, increased risk for second primary cancer, and strong associations with increased cancer treatment toxicity [2, 3]. The adverse effects of smoking can lead to substantial incremental cancer treatment costs, estimated annually at $\$ 10,678$ per patient (equivalent to a total of $\$ 3.4$ billion) for attributable failure of first-line cancer treatment in the US [4]. Smoking cessation can reduce many of these patient risks [5-15], but little consideration has been given to how evidence-based methods can be effectively integrated into standard oncology clinical practice, including the costs associated with tobacco treatment program implementation [1619]. Even though tobacco treatment has been recommended as an essential component of cancer care for those who smoke [20-22], and most cancer organizations [23, 24] and the Surgeon General [25] advocate for providing cessation assistance to cancer patients, most oncology providers do not routinely assist patients to quit smoking [26-28].

To address this research-to-practice gap, the National Cancer Institute (NCI) established the Cancer Center Cessation Initiative (C3I) in 2017 under the Cancer Moonshot Program with the specific objective "to help cancer centers build and implement sustainable programs to routinely address tobacco cessation with cancer patients" [29]. Forty-two NCI-designated cancer centers received funding for 2 years over two funding cycles (2017-2019 for Cohort 1, 2018-2020 for Cohort 2). In 2020, an additional 10 centers received 1 year of funding (Cohort 3). A significant strength of the C3I is its recognition of the need to address multilevel (i.e., programlevel, practice setting, and outer context) factors in the implementation of tobacco treatment programs, such as tobacco screening, integration into clinical workflow, use of information technology, and systematic documentation and outcome reporting.

The present study examined the costs of implementing tobacco treatment programs among the first two cohorts in the C3I during the NCI-funded implementation phase. The C3I provides a compelling infrastructure to study implementation costs for several reasons. First, the initiative requires significant investments from cancer centers to hire tobacco treatment specialists and adapt clinical workflows to integrate tobacco treatment as their clinical standard of care. As costs may be a barrier to 
implementation of tobacco treatment in cancer care broadly, economic evaluations are typically necessary before health systems adopt new initiatives. Further, understanding implementation and operation costs and continuing to pursue cost-effective strategies is key to sustainment of tobacco treatment at participating cancer centers. Therefore, the C3I presents a unique opportunity to investigate the role and implication of costs to tobacco treatment program implementation and sustainability. Whereas early implementation success of the initiative has been recently reported [30,31], implementation costs in the C3I have not been examined.

Costs associated with health system program implementation and operation are infrequently collected but critical for decision makers to ensure program success and sustainment [32]. Demonstrating the economic value of tobacco treatment is important for its integration into routine cancer care processes. One such study from 2009 evaluated the cost-effectiveness of a smoking cessation program implemented at the time of surgery for lung cancer [33] and found the program to be costeffective at both one and 5 years post-surgery. The cost per quality-adjusted life year (QALY) was $\$ 16,415$ at 1 year and $\$ 2609$ at 5 years. In 2005, the Childhood Cancer Survivors Study [34] tested a tobacco cessation intervention consisting of peer-delivered counseling for adult survivors of childhood cancer who smoke. The study concluded that the cost of delivering the intervention was approximately $\$ 300$ per participant, and the incremental cost-effectiveness of the intervention compared with control was $\$ 5371$ per additional quit.

A more recent economic evaluation of smoking cessation programs was conducted in Ontario's regional cancer programs in 2018 using simulation modeling [35]. The study evaluated the cost-effectiveness of two smoking cessation approaches-the prior basic smoking cessation program consisting of screening for tobacco use, advice, and referral and a more intensive program that included cessation medication, counseling, and followup. Compared with the basic program, the intensive program was both more effective and more costly, with an incremental cost-effectiveness ratio of $\$ 3367$ (Canadian dollars) per QALY gained and $\$ 5050$ per life-year gained for males, and \$2050 per QALY gained and \$4100 per life-year gained for females. Given the increasing evidence supporting the health benefits of smoking cessation after a cancer diagnosis [25], economic evidence from cancer care extends the broad evidence base that tobacco treatment programs provide good value compared with other healthcare interventions [36, 37].

The objective of this study was to contribute to our limited understanding of the resources required to implement tobacco treatment programs in cancer care settings and the economic implications of various program designs by estimating the costs of tobacco treatment programs at cancer centers participating in the C3I. Whereas the C3I was implemented based on the promise of earlier search, economic evaluation of the initiative is an essential step to document how C3I builds upon previous efforts in tobacco treatment for cancer patients. In the economic evaluation of implementation efforts, the use of qualitative approaches to complement the quantitative cost data enables the characterization of the contexts and perspectives within which monetary values can be interpreted. This complementary, mixed methods approach is particularly salient in implementation research because the outcomes [38] and costs [39] are highly dependent on contextual factors. Accordingly, this study applied a mixed methods approach [40] to (1) conduct a comparative cost analysis of the various approaches to implementing tobacco treatment programs, and (2) comprehensively describe the economic perspective of C3I implementation by incorporating detailed context-specific information.

\section{Methods \\ Overview}

Of the 42 cancer centers from the first two cohorts of the C3I, 15 centers reported on their operating costs. This study used a mixed methods, comparative case study design, in which each participating site $(n=15)$ is conceptualized as a case [41]. Comparing multiple cases leverages variations across sites and allows for the investigation of contextual factors influencing implementation outcomes, such as cost. Consistent with the objectives of case study research, this study relies on multiple methods of data collection, as the convergence of multiple types of evidence enhances the credibility of the analysis [42]. The study is guided by the Consolidated Health Economic Evaluation Reporting Standards (CHEERS) [43].

\section{Setting}

The setting for this study consisted of NCI-designated cancer centers participating in the C3I program designed to enhance the routine delivery of evidence-based tobacco treatment services. Participating institutions are required to overcome patient, clinician, practice, and health system barriers to providing evidence-based tobacco treatment services to their oncology patients who smoke, to achieve institutional buy-in that treating tobacco use is a component of organizational "standard of care," and to create mechanisms to sustain tobacco treatment services beyond the implementation funding period of the initiative. Several factors position the C3I as a unique setting to evaluate the implementation costs of behavioral interventions in cancer care including the number and diversity in size, structure, and geography of the funded NCI-designated cancer centers; the range 
of implementation strategies and tobacco treatment approaches utilized; and the available reporting on standardized patient outcomes and cost measures.

\section{Data collection procedures}

Tobacco treatment program data were reported by each site to the C3I Coordinating Center for the purposes of program evaluation. The Coordinating Center, based at the University of Wisconsin-Madison Carbone Cancer Center, provides scientific and technical assistance to grantees in integrating evidence-based tobacco treatment services into clinical care [30] and was responsible for data collection across sites. The Coordinating Center has developed metrics to assess the tobacco treatment programs using standard measures for patient outcomes, including reach and effectiveness. Reporting of these metrics to the Coordinating Center was required of each participating site on a twice-annual basis using Qualtrics forms (Qualtrics, Provo, UT). Additionally, cost reporting has been encouraged for sites, following a similar reporting frequency. Cost reporting was first introduced for the July-December 2018 reporting period and we herein include all sites with operating cost data reported at least once during that interval through the JanuaryJune 2020 period. Sites were asked to report their program costs retrospectively using a Qualtrics form that was developed by the lead author in collaboration with the Coordinating Center. Two pilot sites provided feedback on the cost data collection form prior to its rollout to all sites. For qualitative data collection, site visit interviews were conducted by Coordinating Center staff with the director of the cancer center at each site, principal investigator(s) of the C3I project, program staff, clinical or administrative leaders, IT staff, and/or other administrators. The study was determined to be exempt from institutional review board (IRB) approval as there were no patient-level data used, and the study was categorized as program evaluation by the University of WisconsinMadison IRB.

\section{Tobacco treatment program components}

On the twice-annual surveys, sites reported whether they implemented the following types of evidence-based tobacco treatment components: in-person (individual or group) counseling delivered by a tobacco treatment specialist, telephone-based counseling delivered by a tobacco treatment specialist from the program (i.e., internal, other than referral to the quitline), cessation counseling delivered at the point of care, track and triage services delivered by interactive voice response system (i.e., TelASK), referral to the quitline, smokefreeTXT text messaging service, web resources (e.g., smokefree. gov), and cessation medications offered as part of the tobacco treatment program.

\section{Outcome measures}

Standardized metrics were used to report on reach and effectiveness. Program reach was defined as the proportion of current smokers who were offered any type of tobacco treatment program, among current smokers with a clinical visit in the 6-month reporting period. Engagement in a program was defined as participation in an individually or group-delivered counseling program, inperson or via phone, fax or e-referral to a quitline, a website, or a text/mobile program, counseling regarding quitting, or prescribing cessation medication. Effectiveness was defined as the number of current smokers at baseline who engaged in tobacco treatment and reported abstinence from smoking for at least 7 days, among responders at 6-month follow-up. Additional details about outcome measures are reported elsewhere [31].

\section{Estimating resources and costs}

The present study focused on operating (maintenance) costs-i.e., costs to maintain the program after it was developed-as they are most relevant to decision makers. Planning/development costs (e.g., EHR modifications) were inconsistently reported by sites and were not included in the analysis. Research-related costs were excluded as they are not relevant to replicating the program in another setting. The following categories of cost measures were reported by centers: program personnel type and effort, medications provided/covered by the program, educational and training materials, software and technology services (e.g., interactive voice response system), equipment (e.g., computers), and office space. As stated previously, participating sites reported costs for at least one 6-month reporting period, up to a maximum of 3 reporting periods from 2018 to 2020 .

\section{Cost analysis}

We calculated the total operating costs for each site within a 6-month time period by summing reported expenses across all categories. Costs were reported from the perspective of the health system, which is most relevant to decision makers in the case of tobacco treatment program implementation within cancer care settings, as opposed to the patient or societal perspectives. All costs were expressed in local market terms following the guide to costing behavioral interventions developed by Ritzwoller et al. [44]. For the personnel category, effort dedicated to delivering the tobacco treatment program was reported by type of personnel and multiplied by the average wage rates for each personnel type as provided by the Bureau of Labor Statistics [45] for the appropriate metropolitan statistical area of the center. This approach was used to minimize the impact that site-specific variations may have had on intervention cost estimates. Fringe benefits were estimated at $30 \%$ of total salary 
costs for each site. Values were adjusted to 2020 US dollars using the consumer price index to account for inflation [46]. For sites that reported costs for more than one time period, we reported the average cost per category across all available time periods. We converted all costs to monthly costs. We then calculated the cost-perparticipant and cost-per-quit for each site by dividing total operating costs by (1) the number of patients that engaged in tobacco treatment program services within a 6-month period, and (2) the number of patients who reported seven-day abstinence from tobacco use over a 6month time period, respectively. To calculate these two ratios, we used the reach and effectiveness measures reported in the most recent time period, for sites that reported them in more than one time period. Cost-perquit was unavailable for 3 sites that had not yet reported effectiveness data.

\section{Site visit interviews}

Researchers from the C3I Coordinating Center with expertise in qualitative methodology, tobacco cessation, and health systems research developed the interview guide, informed by the Consolidated Framework for Implementation Research (CFIR) [47]. Copies of the interview guide are available from the Coordinating Center upon request. Program leaders and staff were asked about program components, the implementation process, barriers and facilitators, and the resources needed to maintain the program over time. Interviews followed a semi-structured format in which respondents were asked the same questions with the opportunity for customized follow-up and suggested probes depending on responses. Interviews were transcribed verbatim, cross-checked by another team member, and analyzed by a team of two researchers using NVivo version 11 (QSR International), a qualitative data management program.

\section{Qualitative data analysis}

The research team first conducted queries of coded transcripts from sites that reported cost data to extract content relevant to implementation barriers, implementation facilitators, and resources needed for program sustainability. Queries underwent secondary inductive coding for emerging themes, which were compiled and grouped according to constructs in the Consolidated Framework for Implementation Research (CFIR) [47] related to intervention characteristics, inner setting, and implementation process. Themes most relevant to understanding costs and resource needs for implementation were identified and added to the site-level matrix, allowing for a side-by-side comparison of quantitative and qualitative findings on costs specific to each site. Interpretation of findings followed a concurrent mixed methods approach, whereby qualitative findings complemented quantitative findings with information on contextual factors related to costs of implementation; and (2) intangible resource factors (e.g., time, space) that are difficult to collect in a quantitative format.

\section{Results}

Tobacco treatment program services

Table 1 presents the tobacco treatment program components offered at each site, numbered 1 through 15 .

Table 1 Tobacco treatment program types offered at each site

\begin{tabular}{|c|c|c|c|c|c|c|c|c|c|}
\hline Site & Site & $\begin{array}{l}\text { In-person } \\
\text { counseling }\end{array}$ & $\begin{array}{l}\text { Telephone-based } \\
\text { counseling }\end{array}$ & Point of care & $\begin{array}{l}\text { Interactive voice } \\
\text { response system }\end{array}$ & $\begin{array}{l}\text { Referral to } \\
\text { quitline }\end{array}$ & Smokefree TXT & $\begin{array}{l}\text { Web resource } \\
\text { (e.g., smokefree.gov) }\end{array}$ & $\begin{array}{l}\text { Cessation } \\
\text { medications }\end{array}$ \\
\hline $8^{\mathrm{a}}$ & $1^{a}$ & $\checkmark$ & & $\checkmark$ & & $\checkmark$ & $\checkmark$ & $\checkmark$ & $\checkmark$ \\
\hline $14^{\mathrm{a}}$ & $2^{a}$ & $\checkmark$ & $\checkmark$ & $\checkmark$ & $\checkmark$ & $\checkmark$ & $\checkmark$ & $\checkmark$ & $\checkmark$ \\
\hline $15^{\mathrm{b}}$ & $3^{b}$ & $\checkmark$ & & & & $\checkmark$ & & & $\checkmark$ \\
\hline $5^{a}$ & $4^{\mathrm{a}}$ & & $\checkmark$ & $\checkmark$ & & & & & $\checkmark$ \\
\hline $6^{\mathrm{a}}$ & $5^{a}$ & $\checkmark$ & $\checkmark$ & $\checkmark$ & $\checkmark$ & $\checkmark$ & & & $\checkmark$ \\
\hline $12^{\mathrm{b}}$ & $6^{\mathrm{b}}$ & $\checkmark$ & $\checkmark$ & & & $\checkmark$ & $\checkmark$ & $\checkmark$ & $\checkmark$ \\
\hline $7^{\mathrm{a}}$ & $7^{\mathrm{a}}$ & & & & & $\checkmark$ & & & $\checkmark$ \\
\hline $1^{\mathrm{a}}$ & $8^{a}$ & $\checkmark$ & $\checkmark$ & $\checkmark$ & & & & & $\checkmark$ \\
\hline $11^{\mathrm{b}}$ & $9^{b}$ & $\checkmark$ & $\checkmark$ & $\checkmark$ & & $\checkmark$ & $\checkmark$ & $\checkmark$ & $\checkmark$ \\
\hline $4^{a}$ & $10^{\mathrm{a}}$ & $\checkmark$ & & & & $\checkmark$ & & & \\
\hline $2^{\mathrm{a}}$ & $11^{a}$ & $\checkmark$ & $\checkmark$ & $\checkmark$ & & $\checkmark$ & & & $\checkmark$ \\
\hline $10^{b}$ & $12^{\mathrm{b}}$ & $\checkmark$ & $\checkmark$ & $\checkmark$ & & $\checkmark$ & & $\checkmark$ & $\checkmark$ \\
\hline $13^{\mathrm{b}}$ & $13^{\mathrm{b}}$ & $\checkmark$ & & & & $\checkmark$ & & $\checkmark$ & $\checkmark$ \\
\hline $9^{a}$ & $14^{\mathrm{a}}$ & $\checkmark$ & & & $\checkmark$ & $\checkmark$ & $\checkmark$ & & $\checkmark$ \\
\hline $3^{a}$ & $15^{\mathrm{a}}$ & $\checkmark$ & $\checkmark$ & & & & & $\checkmark$ & $\checkmark$ \\
\hline
\end{tabular}

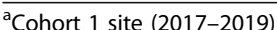

${ }^{\mathrm{b} C o h o r t} 2$ site (2018-2020) 
Among the 15 sites, 10 sites were from Cohort 1 (20172019) and 5 sites were from Cohort 2 (2018-2020). Tobacco treatment programs at these sites were launched in 2017 or earlier (3 sites), 2018 (8 sites), and 2019 (4 sites, results not shown). The number of treatment components offered varied widely across centers. For example, Site 4 offered only individually delivered inperson tobacco treatment and referral to the quitline, whereas Site 14 offered all treatment components. Among the 15 sites, 13 offered in-person counseling (either individually or group-delivered), and 9 sites offered telephone-based counseling. In addition, 8 sites offered point-of-care interventions, 3 deployed an interactive voice response system, 12 referred patients to the state quitline, 5 offered the SmokefreeTXT service, 7 offered web-based resources, and 14 offered patients cessation medications.

\section{Costs per site}

Monthly operating costs are reported in Table 2. Total operating costs per month ranged from $\$ 5129$ to $\$ 20$, 751 , with a median of $\$ 11,045$. The highest costs were typically reported in the personnel category, which ranged from $\$ 4122$ to $\$ 19,794$ with a median of $\$ 10,307$ (representing $90 \%$ of median total monthly costs). Only 5 sites reported medication costs to the health system, ranging from $\$ 17$ to $\$ 573$ in total monthly costs. While some patients may have had coverage for cessation medications through their health plans, select programs reported offering medications as a treatment benefit.
Additionally, 10 sites reported educational material costs, ranging from $\$ 6$ to $\$ 435$ per month; 12 sites reported training costs, ranging from $\$ 96$ to $\$ 516$ per month; 6 sites reported technology costs, ranging from $\$ 171$ to $\$ 4167$ per month; 12 sites reported equipment costs, ranging from $\$ 10$ to $\$ 620$ per month; and 6 sites reported other operating costs (e.g., biochemical verification), ranging from $\$ 36$ to $\$ 337$ per month.

\section{Cost per participant and cost per quit}

Table 3 presents cost-per-participant and cost-per-quit across sites. The number of participants, varied widely, ranging from 32 to 935 participants per site, with patient engagement ranging from $2.1 \%$ to $85 \%$. The quit rate (i.e., effectiveness) also varied by site from a low of $6.7 \%$ to a high of $34.4 \%$. Cost-per-participant ranged from $\$ 70$ to $\$ 2093$, with a median of $\$ 466$, while cost-per-quit ranged from $\$ 330$ to $\$ 9628$, with a median of $\$ 2688$. Cost-per-quit was less than $\$ 3500$ at 9 of the 12 sites that had available data.

\section{Contextual cost-related factors influencing program implementation and delivery}

Site interviews provided context for understanding costs related to personnel, technology, and equipment, and complemented quantitative findings with information about other resource-related factors such as available time and space. These factors were identified as barriers and facilitators to program implementation and were also mentioned in response to questions regarding

Table 2 Monthly operating costs (\$) per site, by expense category and (\%) of total cost

\begin{tabular}{|c|c|c|c|c|c|c|c|c|c|}
\hline Site & Personnel & Medications & Materials & Training & Technology & Equipment & Other & Total cost & Reporting periods \\
\hline 1 & 10,307 (95.1) & - & $17(0.2)$ & - & $513(4.7)$ & - & - & 10,838 & 2 \\
\hline 2 & $19,794(95.4)$ & - & $131(0.6)$ & $282(1.4)$ & $171(0.8)$ & $79(0.4)$ & $337(1.6)$ & 20,751 & 3 \\
\hline 3 & $6878(62.3)$ & - & - & - & $4167(37.7)$ & - & - & 11,045 & 1 \\
\hline 4 & $11,744(90.0)$ & - & - & $513(3.9)$ & $257(2.0)$ & $539(4.1)$ & - & 13,052 & 1 \\
\hline 5 & $13,518(95.5)$ & - & $6(0.0)$ & $175(1.2)$ & - & $453(3.2)$ & - & 14,152 & 3 \\
\hline 6 & $17,542(99.0)$ & - & $168(1.0)$ & - & - & - & - & 17,710 & 2 \\
\hline 7 & $8400(90.2)$ & $454(4.9)$ & $7(0.1)$ & $134(1.4)$ & - & $268(2.9)$ & $50(0.5)$ & 9314 & 1 \\
\hline 8 & $6641(86.9)$ & - & - & $390(5.1)$ & - & $611(8.0)$ & - & 7642 & 1 \\
\hline 9 & 17,455 (92.8) & $17(0.1)$ & $35(0.2)$ & $485(2.6)$ & - & $537(2.9)$ & $288(1.5)$ & 18,817 & 3 \\
\hline 10 & 5881 (91.1) & - & - & $376(5.8)$ & - & $196(3.0)$ & - & 6453 & 1 \\
\hline 11 & $11,046(97.2)$ & - & 178 (1.6) & $96(0.8)$ & - & $10(0.1)$ & $36(0.3)$ & 11,367 & 3 \\
\hline 12 & 8346 (82.7) & $573(5.7)$ & 366 (3.7) & 377 (3.8) & - & $227(2.3)$ & $122(1.2)$ & 10,010 & 3 \\
\hline 13 & 4558 (88.9) & - & - & $220(4.3)$ & - & 186 (3.6) & $164(3.2)$ & 5129 & 2 \\
\hline 14 & 4122 (48.8) & $121(1.4)$ & 309 (3.7) & $516(6.1)$ & $2759(32.7)$ & $620(7.3)$ & - & 8447 & 2 \\
\hline 15 & 14,103 (87.9) & $51(0.3)$ & $435(2.7)$ & 359 (2.2) & $889(5.4)$ & 209 (1.3) & - & 16,046 & 1 \\
\hline Median & $10,307(90.0)$ & 0 & $17(0.1)$ & $282(2.2)$ & 0 & 209 (1.6) & 0 & 11,045 & \\
\hline Minimum & 4122 & 0 & 0 & 0 & 0 & 10 & 0 & 5129 & \\
\hline Maximum & 19,794 & 573 & 435 & 516 & 4167 & 620 & 337 & 20,751 & \\
\hline
\end{tabular}


Table 3 Cost per participant and cost per quit across sites, in descending order by number of treatment participants

\begin{tabular}{|c|c|c|c|c|c|c|c|}
\hline Site & $\begin{array}{l}\text { Patients, current } \\
\text { smokers }(n)\end{array}$ & $\begin{array}{l}\text { Treatment } \\
\text { participants }(n)\end{array}$ & $\begin{array}{l}\text { Patient } \\
\text { engagement (\%) }\end{array}$ & $\begin{array}{l}\text { Cost per } \\
\text { participant (\$) }\end{array}$ & Quits $(n)^{\mathrm{a}}$ & Quit rate (\%) & Cost per quit (\$) \\
\hline 1 & 2847 & 935 & 32.8 & 70 & 197 & 21.1 & 330 \\
\hline 2 & 2342 & 557 & 23.8 & 224 & 57 & 10.2 & 2184 \\
\hline 3 & 1591 & 404 & 25.4 & 164 & 43 & 10.6 & 1541 \\
\hline 4 & 702 & 360 & 51.3 & 218 & 24 & 6.7 & 3263 \\
\hline 5 & 2499 & 247 & 9.9 & 344 & 40 & 16.2 & 2123 \\
\hline 6 & 570 & 198 & 34.7 & 537 & 38 & 19.2 & 2796 \\
\hline $7^{\mathrm{b}}$ & 1694 & 120 & 7.1 & 466 & - & - & - \\
\hline 8 & 239 & 96 & 40.2 & 478 & 19 & 19.8 & 2413 \\
\hline 9 & 1268 & 90 & 7.1 & 1254 & 31 & 34.4 & 3642 \\
\hline 10 & 460 & 86 & 18.7 & 450 & 14 & 16.3 & 2766 \\
\hline 11 & 512 & 75 & 14.6 & 909 & 17 & 22.7 & 4012 \\
\hline 12 & 293 & 74 & 25.3 & 812 & 23 & 31.1 & 2611 \\
\hline $13^{b}$ & 1489 & 67 & 4.5 & 459 & - & - & - \\
\hline $14^{\mathrm{b}}$ & 178 & 65 & 36.5 & 780 & - & - & - \\
\hline 15 & 203 & 46 & 22.7 & 2093 & 10 & 21.7 & 9628 \\
\hline Median & 702 & 96 & 23.8 & 466 & 28 & 19.2 & 2688 \\
\hline Minimum & 178 & 46 & 4.5 & 70 & 10 & 6.7 & 330 \\
\hline Maximum & 2847 & 935 & 51.3 & 2093 & 197 & 34.4 & 9628 \\
\hline
\end{tabular}

${ }^{a}$ The number of participants and number of quits were based on the most recent reporting period. The quit rates were calculated based on 7-day pointprevalence among participants who responded to 6 months follow-up. Quits $(n)$ were observed during the same period but represent the patients enrolled in the previous 6 months

${ }^{\mathrm{b}}$ Number of quits was not reported for these sites

program needs for sustainability. In terms of overall program funding, sites mentioned several facilitators, including initial funding support from the NCI and matching funds from the cancer center or healthcare system (e.g., Sites 7, 12, and 15), as well as industry support in the form of cessation medication donations (e.g., Site 15). Several sites that received an initial commitment of funding support from either the cancer center or healthcare system (e.g., Sites 4, 7, 8, 11, and 14) were also considering business models for sustainability that would include billing for tobacco treatment services. Meanwhile, Site 8 embraced a paradigm shift to point of care smoking cessation as a strategy to address suboptimal referral rates and unsustainable program funding. Site 5, which also received a commitment from the cancer center for additional funding, expressed concern about the pressures of seeking grant funding to sustain the program. Respondents at all sites were asked what resources they would need to sustain their program in the long-term. Responses revealed needed resources, which were not yet available at the site but believed to be necessary for sustainability. Specific staffing needs included the need for additional full-time tobacco treatment specialists to "reach scale" or to administer telephone counseling, a community educator, a "dedicated person for cancer," support staff after the end of supplement funding, and staff dedicated to long-term follow-up.

\section{Discussion}

This study is the first to our knowledge to examine the economic implications of implementing tobacco treatment programs within cancer centers on a national scale. Health care decision makers often request information showing how a new treatment program will affect their budget. Accordingly, economic evaluations are important to guiding the implementation and sustainment of tobacco treatment programs in oncology and other clinical settings.

Implementing and sustaining tobacco treatment programs in cancer centers requires resources, most notably personnel time, which are often not documented when the results of the program implementation are presented in the literature. In the present mixed methods study, we examined the costs of implementing tobacco treatment programs at $15 \mathrm{NCI}$-designated cancer centers participating in the C3I, along with the contextual information about the resources and other related costs, such as time and space, associated with these implementation efforts. These programs had a median monthly cost of $\$ 11,045$, with the bulk of costs dedicated to program personnel. The findings suggest that tobacco treatment 
programs implemented in cancer care settings achieve noteworthy quit rates for relatively modest costs. While many of the participating centers were in the early stages of implementation, the median cost-per-quit was $\$ 2781$ among sites with available data. In comparison, the costper-quit based on implementing the clinical practice guideline for tobacco treatment was estimated at $\$ 3779$ (in 1995 dollars), equivalent to $\$ 6500$ (in 2020 dollars) [37]. Overall, the cost-effectiveness of these programs is expected to improve as programs mature and achieve greater efficiency and higher patient engagement over time.

It is noteworthy that the cost-per-quit at many C3I sites is generally within the range of historical costeffectiveness estimates for tobacco treatment, even though each of the sites implemented markedly different tobacco treatment program components. More specifically, Site 8 achieved the lowest cost-per-quit using a point-of-care model in which oncology providers referred patients to quitline services. The point-of-care intervention was considered part of standard care and did not contribute costs to the tobacco treatment program. Yet, Site 5 had one of the lowest cost-per-quit rates despite primarily offering individually delivered counseling services, arguably the most labor-intensive option. In comparison, Site 2 achieved modest cost-perquit while offering all categories of tobacco treatment components, by taking a dual approach of promoting high reach services as a population-based approach while offering high-intensity services to a subgroup of patients. Meanwhile, the remaining sites offered a subset of services that included a combination of moreintensive and less-intensive options. In addition, costper-quit across all programs is lower than the incremental costs attributed to failure of first-line cancer treatment associated with smoking after a cancer diagnosi $s[4]$. As these programs mature over time, an important empirical question is whether there will be more divergence in cost-per-quit according to program components, characteristics of patients served and geographic location of cancer centers. Meanwhile, the higher costper-participant and cost-per-quit observed at other sites may be at least in part due to the fact that these programs could still be in the early stages of implementation and may not have reached full capacity. Additionally, quit rates could be underreported across sites, as some tobacco treatment participants who quit may have been lost to follow up at 6 months.

Given budget constraints, sites must balance between prioritizing program reach and effectiveness. Among sites that achieved similar cost-per-quit rates, a subset of sites reported high quit rates (e.g., 34\%) while engaging a relatively small number of patients (i.e., fewer than 100 participants). Alternatively, other sites have achieved high engagement (e.g., more than 500 participants) with lower quit rates (e.g., 10\%). Given that the C3I did not dictate uniform program components across all sites, centers had the freedom to choose program designs that optimize fit within the local context. For example, several sites achieved low cost-per-quit by relying heavily on referrals to the state quitline. However, variations across state quitlines in terms of funding, services provided, and eligibility criteria suggest that this may not be an equally reliable option for other cancer centers. Overall, several sites achieved above-average rates in both engagement and effectiveness (Sites 1, 6, 8, and 12) while maintaining relatively low cost-per-quit (less than $\$ 3000$ ). Whereas the clinical practice guideline for tobacco treatment has been clear about the effectiveness of tobacco cessation interventions, the C3I experience suggests that different intervention forms may achieve similar cost-effectiveness. Future research should further examine the relative cost-effectiveness of different tobacco treatment intervention forms with more granular data that include patient-level metrics for the various tobacco treatment services offered at each site.

Despite convincing evidence on the cost-effectiveness of tobacco treatment interventions [36] and a high willingness to support them by clinicians [48], implementation of tobacco treatment programs into clinical oncology practice might be hampered due to specific economic barriers that represent disincentives for health systems to implement such programs. One key issue in the implementation and dissemination of evidence-based practices in clinical settings is the identification of funding sources for program development and sustainment. Whereas the C3I has provided funding for the development of tobacco treatment programs at cancer centers, the sustainability of these programs remains a challenge. However, as a condition of participation in the C3I, centers made a commitment to maintain their programs beyond the initial period of NCI support. This initial commitment from the centers has been secured largely with institutional funds, however many sites have identified opportunities for partial cost recovery, mainly by seeking reimbursement for tobacco treatment services.

Tobacco treatment is an example of an intervention for which the evidence on the value and costeffectiveness is convincing [36], and therefore, implementation in clinical practice is warranted. As an example, findings from the current study serve as a reminder that pharmacotherapy-an intervention with demonstrated population-level effectiveness in cancer patients [49] and offered by the majority of the participating sites-can be offered at low or no cost to the health care system. However, the lack of explicit priority-setting about implementation of tobacco treatment and the potential conflicts among the stakeholders 
in the health system are critical barriers. Also, behavioral factors in individual health professionals, such as clinical inertia and persistent routine behaviors, may inhibit change. Therefore, implementation of tobacco treatment programs as evidence-based, cost-effective practices does not follow automatically, as there are barriers for change at multiple levels that must be addressed [50-52].

Additional research is needed to improve the understanding of economic barriers and facilitators to the adoption and sustainment of tobacco treatment programs in oncology settings. Future research should also consider strategies to inform decision makers on coverage for tobacco treatment as an alternative for current fee-for-service models that do not allow for the integration of sustainable intensive tobacco cessation counseling into cancer care [53]. Given that fee-for-service reimbursement is predicated upon evaluation and management physician billing codes for treatment, intensive counseling delivered by unlicensed tobacco treatment specialists can only be reimbursed at low rates using preventive counseling codes. The current reimbursement rates do not incentivize additional counseling and are insufficient to sustain intensive cessation counseling [53]. However, programs that employ tobacco treatment specialists with either a social work degree (e.g., LCSW) or psychology degree (e.g., $\mathrm{PhD} / \mathrm{PsyD}$ ) can indeed bill at higher rates, but face higher labor costs. Accordingly, economic methods can play a critical role to support the business case for sustainable tobacco treatment programs as a worthwhile investment of the limited resources of health systems. Further, the recent diffusion of digital and telehealth approaches offers opportunities to enhance the cost-effectiveness of tobacco treatment over more in-person, high-touch approaches.

The present study had a number of strengths, including the evaluation of tobacco treatment program implementation costs within a large cohort of cancer centers across the US, comprehensive cost estimates for these programs, and the use of quantitative and qualitative interview data to estimate and interpret the comparative cost-effectiveness of tobacco treatment programs. The C3I is the first initiative of its kind and has been leading the implementation of evidence-based tobacco treatment programs across NCI-designated cancer centers nationwide. The initiative has produced unique information that can improve our understanding of tobacco treatment in oncology settings, including implementation costs. The mixed methods approach used in this study provides insights on contextual information and stakeholder perspectives beyond findings captured by monetary values alone.

Limitations included the retrospective nature of cost data collection. The level of accuracy of reported costs may have been compromised due to retrospective cost reporting and the fact that tobacco treatment resources may have been shared by oncology and other units within the health system. Whereas most sites focused their C3I efforts on the outpatient setting, where it is easier to track cancer patients separately from other patients, some C3I sites also included tobacco treatment programs in the inpatient setting, where tobacco treatment resources may be shared with non-cancer patients. In those instances, it was more challenging to isolate the resources that were attributable to treating tobacco use specifically among cancer patients, which may have led to overestimating cost-per-quit. Similarly, at least one cancer center (Site 12) provides tobacco treatment to other outpatient specialties, incurring costs without capturing those patients' outcomes data in C3I reporting. Among the many centers that referred patients to the quitline, cost-per-quit may depend on the quality of the quitline available in their state. As the present analysis was limited to the health system perspective, it does not reflect the actual public cost of the tobacco treatment programs. In addition, program effectiveness is measured by short-term assessment of quits, which may differ over the long term. As such, long-term assessment of both costs and outcomes is required to fully explore the cost-effectiveness of the tobacco treatments offered. Higher intensity interventions may be more costly to implement, but they may also be more effective over time.

Although all sites reported the range of tobacco treatment services they offered, the reporting was not granular enough to reflect specific treatment enrollment at the patient level. Therefore, we were unable to ascertain the relative effectiveness and cost-effectiveness of treatment services at the site level. Also, given the variations across programs, we were unable to estimate the marginal impact of each component. Further, given that cost reporting was voluntary for C3I sites, response bias may be a potential factor. Although sites may not have participated in cost reporting because they had not sufficiently progressed in implementation at the time of this report, confounding factors (e.g., limited personnel) may have contributed to other sites not reporting their cost information. This limitation may have been exacerbated by the COVID-19 pandemic in the 2020 reporting period. In addition, the C3I is an ongoing initiative, and effectiveness data were unavailable for some sites. Also, with respect to effectiveness, quit rates were based on patient self-report and abstinence was not biochemically verified at the vast majority of sites. Therefore, the accuracy of quit rates may be questionable. Finally, findings from this study were based on the experiences of NCIdesignated cancer centers, which typically have more resources than other cancer centers. Although study findings may not be entirely generalizable to other cancer centers, the implementation costs as well as the 
resource-related barriers and facilitators summarized in this study could inform the implementation of tobacco treatment programs across all cancer centers.

\section{Conclusions}

Costs are a key consideration in the decision to offer tobacco treatment services within health care delivery settings, and oncology care is no exception. Overall, tobacco treatment programs implemented within NCIdesignated cancer centers resulted in modest cost-perquit, regardless of program design. These findings can inform and guide program developers, providers, and implementers with the design and implementation of these programs in similar target populations while ensuring resources are efficiently allocated to maximize value in cancer care. The demonstrable value of tobacco treatment programs should serve to inform the systemlevel change that is needed to support the sustainment of smoking cessation services in cancer care.

\section{Abbreviations}

C3I: Cancer center cessation initiative; NCl: National cancer institute; CHEE RS: Consolidated health economic evaluation reporting standards;

EHR: Electronic health record

\section{Acknowledgements}

We would like to thank the tobacco treatment program staff at participating cancer centers for their support in data collection.

\section{Authors' contributions}

RGS, HD'A, RPT, BR, WBV, GWW, and MF contributed to the conception and design of the study. RGS analyzed the cost data and wrote the first draft. RPT, HD'A, SH, DP, and JHL contributed to the analysis and interpretation of interview data. HD'A and RPT wrote sections of the manuscript. YA, L-SC, AD, $A O G, B H, D H, A C K, C Y L, K L, A H L, J P, F S, K T, J T, H T$, ET, and JSW contributed to the acquisition of data and manuscript revision. All authors read and approved the final manuscript.

\section{Funding}

A contract from the National Cancer Institute (ICF Contract \#17GZSK0031) supported the implementation of tobacco treatment programs and data reporting at the $\mathrm{NCl}$-designated cancer centers and coordination efforts at the University of Wisconsin.

\section{Availability of data and materials}

The datasets generated and analyzed during the study are not publicly available due to the sensitive nature of cost data but are available from the C3l coordinating center on reasonable request.

\section{Declarations}

\section{Ethics approval and consent to participate}

Data reported in this manuscript were collected for the purposed of program evaluation and quality improvement. The need for informed consent of participants was waived because programs participating in the evaluation provided deidentified, aggregated data. The evaluation was approved by the Institutional Review Board of the University of Wisconsin Madison.

\section{Consent for publication}

We consent to publication.

\section{Competing interests}

The authors declare that the research was conducted in the absence of any commercial or financial relationships that could be construed as a potential conflict of interest.

\section{Author details}

'Department of Health Outcomes and Biomedical Informatics, University of Florida College of Medicine, 2004 Mowry Road, Gainesville, FL, USA.

${ }^{2}$ University of Wisconsin Carbone Cancer Center, Madison, WI, USA.

${ }^{3}$ University of Wisconsin Institute for Clinical and Translational Research, Madison, WI, USA. ${ }^{4}$ Rush University Medical Center and Rush Cancer Center, Chicago, IL, USA. ${ }^{5}$ Washington University Siteman Cancer Center, St Louis, MO, USA. 'University of Texas Southwestern Medical Center, Dallas, TX, USA. ${ }^{7}$ University of North Carolina Lineberger Cancer Center, Chapel Hill, NC, USA. ${ }^{8}$ Northwestern University Feinberg School of Medicine and Lurie

Comprehensive Cancer Center of Northwestern University, Chicago, IL, USA. ${ }^{9}$ Indiana University Simon Cancer Center, Indianapolis, IN, USA. ${ }^{10}$ University of Chicago Medicine Comprehensive Cancer Center, Chicago, IL, USA.

${ }^{11}$ Huntsman Cancer Institute, University of Utah, Salt Lake City, UT, USA.

${ }^{12}$ Dartmouth-Hitchcock Norris Cotton Cancer Center, Lebanon, NH, USA.

${ }^{13}$ University of Colorado Comprehensive Cancer Center, Aurora, CO, USA.

${ }^{14}$ Stanford Cancer Institute, Stanford University, Stanford, CA, USA. ${ }^{15}$ Barbara Ann Karmanos Cancer Institute, Detroit, MI, USA. ${ }^{16}$ Georgetown University Lombardi Comprehensive Cancer Center, Washington, DC, USA. ${ }^{17}$ University of Minnesota Masonic Cancer Center, Minneapolis, MN, USA. ${ }^{18}$ Vanderbilt University Medical Center Vanderbilt-Ingram Cancer Center, Nashville, TN, USA. ${ }^{19}$ University of California Davis Comprehensive Cancer Center, Sacramento, CA, USA. ${ }^{20}$ Philip R. Lee Institute for Health Policy Studies, University of California, San Francisco, CA, USA. ${ }^{21}$ Medical University of South Carolina Hollings Cancer Center, Charleston, SC, USA. ${ }^{22}$ University of Wisconsin Center for Tobacco Research and Intervention, Madison, WI, USA.

Received: 24 January 2021 Accepted: 1 April 2021

Published online: 09 April 2021

\section{References}

1. Salloum RG, Huo J, Lee JH, Lee J, Dallery J, George T, et al. Tobacco and Ecigarette use among cancer survivors in the United States. PLoS One. 2019; 14(12):e0226110. https://doi.org/10.1371/journal.pone.0226110.

2. Warren GW, Alberg AJ, Kraft AS, Cummings KM. The 2014 Surgeon General's Report: The Health Consequences of Smoking - 50 Years of Progress - A Paradigm Shift in Cancer Care. Cancer. 2014;120(13):1914-6. https://doi. org/10.1002/cncr.28695.

3. US Department of Health and Human Services. The health consequences of smoking - 50 years of progress: a report of the Surgeon General. Atlanta, GA: US Department of Health and Human Services, Centers for Disease Control and Prevention; 2014.

4. Warren GW, Cartmell KB, Garrett-Mayer E, Salloum RG, Cummings KM. Attributable failure of first-line cancer treatment and incremental costs associated with smoking by patients with cancer. JAMA Netw Open. 2019; 2(4):e191703. https://doi.org/10.1001/jamanetworkopen.2019.1703.

5. Nia PS, Weyler J, Colpaert C, Vermeulen P, Van Marck E, Van Schil P. Prognostic value of smoking status in operated non-small cell lung cancer. Lung Cancer. 2005;47(3):351-9.

6. Chen J, Jiang R, Garces $Y$ I, Jatoi A, Stoddard SM, Sun Z, et al. Prognostic factors for limited-stage small cell lung cancer: a study of 284 patients. Lung Cancer. 2010;67(2):221-6. https://doi.org/10.1016/j. lungcan.2009.04.006.

7. Roach MC, Rehman S, DeWees TA, Abraham CD, Bradley JD, Robinson CG. It's never too late: Smoking cessation after stereotactic body radiation therapy for non-small cell lung carcinoma improves overall survival. Pract Radiat Oncol. 2016;6(1):12-8. https://doi.org/10.1016/j.prro.2015.09.005.

8. Tao L, Wang RW, Gao YT, Yuan JM. Impact of postdiagnosis smoking on long-term survival of cancer patients: the Shanghai cohort study. Cancer Epidem Biomar. 2013;22(12):2404-11. https://doi.org/10.1158/1055-9965. EPI-13-0805-T

9. Browman GP, Mohide EA, Willan A, Hodson I, Wong G, Grimard L, et al. Association between smoking during radiotherapy and prognosis in head and neck cancer: a follow-up study. Head Neck. 2002;24(12):1031-7. https:// doi.org/10.1002/hed.10168. 
10. Amato KAD, Hyland A, Reed R, Mahoney MC, Marshall J, Giovino G, et al. Tobacco cessation may improve lung cancer patient survival. J Thorac Oncol. 2015;10(7):1014-9. https://doi.org/10.1097/JTO.0000000000000578.

11. Choi SH, Terrell JE, Bradford CR, Ghanem T, Spector ME, Wolf GT, et al. Does quitting smoking make a difference among newly diagnosed head and neck cancer patients? Nicotine Tob Res. 2016;18(12):2216-24. https://doi. org/10.1093/ntr/ntw189.

12. Passarelli MN, Newcomb PA, Hampton JM, Trentham-Dietz A, Titus LJ, Egan $\mathrm{KM}$, et al. Cigarette smoking before and after breast cancer diagnosis: mortality from breast cancer and smoking-related diseases. J Clin Oncol. 2016;34(12):1315-22. https://doi.org/10.1200/JCO.2015.63.9328.

13. Yang BY, Jacobs EJ, Gapstur SM, Stevens V, Campbell PT. Active smoking and mortality among colorectal cancer survivors: the cancer prevention study II nutrition cohort. J Clin Oncol. 2015;33(8):885-93. https://doi.org/1 0.1200/JCO.2014.58.3831.

14. Garden AS, Kies MS, Morrison WH, Weber RS, Frank SJ, Glisson BS, et al. Outcomes and patterns of care of patients with locally advanced oropharyngeal carcinoma treated in the early 21 st century. Radiat Oncol. 2013;8(1). https://doi.org/10.1186/1748-717X-8-21.

15. Warren G, Simmons VN. Tobacco use and the cancer patient. In: Principles and Practice of Oncology. 11 edn.; 2018.

16. Rojewski AM, Baldassarri S, Cooperman NA, Gritz ER, Leone FT, Piper ME, et al. Exploring issues of comorbid conditions in people who smoke. Nicotine Tob Res. 2016;18(8):1684-96. https://doi.org/10.1093/ntr/ntw016.

17. Rojewski AM, Bailey SR, Bernstein SL, Cooperman NA, Gritz ER, Karam-Hage $M A$, et al. Considering systemic barriers to treating tobacco use in clinical settings in the United States. Nicotine Tob Res. 2019;21(11):1453-61. https:// doi.org/10.1093/ntr/nty123.

18. Warren GW, Sobus S, Gritz ER. The biological and clinical effects of smoking by patients with cancer and strategies to implement evidence-based tobacco cessation support. Lancet Oncol. 2014;15(12):E568-80. https://doi. org/10.1016/S1470-2045(14)70266-9.

19. Warren GW, Ward KD. Integration of tobacco cessation services into multidisciplinary lung cancer care: rationale, state of the art, and future directions. Transl Lung Cancer R. 2015;4(4):339-52.

20. Fiore MC, D'Angelo $H$, Baker T. Effective cessation treatment for patients with cancer who smoke -the fourth pillar of cancer Care. JAMA Netw Open. 2019;2(9):e1912264. https://doi.org/10.1001/jamanetworkopen.2019.12264.

21. Fiore MC, Jaén CR, Baker TB, Bailey WC, Benowitz NL, Curry SJ, et al. Treating tobacco use and dependence: 2008 update. Rockville, MD: US Department of Health and Human Services; 2008.

22. Shields PG, Herbst RS, Arenberg D, Benowitz NL, Bierut L, Luckart JB, et al. Smoking Cessation, Version 1.2016 Clinical Practice Guidelines in Oncology. J Natl Compr Canc Netw. 2016;14(11):1430-68. https://doi.org/10.6004/ jncen.2016.0152.

23. Gritz ER, Toll BA, Warren GW. Tobacco use in the oncology setting: advancing clinical practice and research. Cancer Epidemiol Biomarkers Prev. 2014;23(1):3-9. https://doi.org/10.1158/1055-9965.EPI-13-0896.

24. Land SR, Toll BA, Moinpour CM, Mitchell SA, Ostroff JS, Hatsukami DK, et al. Research priorities, measures, and recommendations for assessment of tobacco use in clinical cancer research. Clin Cancer Res. 2016;22(8):1907-13. https://doi.org/10.1158/1078-0432.CCR-16-0104.

25. US Department of Health and Human Services. Smoking Cessation: A report of the Surgeon General. Atlanta, GA: US Department of Health and Human Services, Centers for Disease Control and Prevention; 2020.

26. Warren GW, Marshall JR, Cummings M, Toll B, Gritz ER, Hutson A, et al. Practice patterns and perceptions of thoracic oncology providers on tobacco use and cessation in cancer patients. J Thorac Oncol. 2013;8(5): 543-8. https://doi.org/10.1097/JTO.0b013e318288dc96.

27. Warren GW, Marshall JR, Cummings KM, Toll BA, Gritz ER, Hutson A, et al. Addressing tobacco use and cessation in cancer patients: practices, perceptions, and barriers reported by oncology providers. J Clin Oncol. 2013;31(15):1561.

28. Goldstein AO, Ripley-Moffitt CE, Pathman DE, Patsakham KM. Tobacco use treatment at the US National Cancer Institute's designated cancer centers. Nicotine Tob Res. 2013;15(1):52-8. https://doi.org/10.1093/ntr/nts083.

29. Croyle RT, Morgan GD, Fiore MC. Addressing a Core Gap in Cancer Care The $\mathrm{NCl}$ moonshot program to help oncology patients stop smoking. New Engl J Med. 2019;380(6):512-5. https://doi.org/10.1056/NEJMp1813913.

30. D'Angelo H, Rolland B, Adsit R, Baker TB, Rosenblum M, Pauk D, et al. Tobacco treatment program implementation at $\mathrm{NCl}$ cancer centers: progress of the $\mathrm{NCl}$ cancer moonshot-funded cancer center cessation initiative. Cancer Prev Res. 2019;12(11):735-40. https://doi.org/10.1158/19406207.CAPR-19-0182.

31. D'Angelo H, Ramsey AT, Rolland B, Chen L, Bernstein SL, Fucito LM, et al. Pragmatic application of the RE-AIM framework to evaluate the implementation of tobacco cessation programs within $\mathrm{NCl}$-designated cancer centers. Front Public Health. 2020;8:221

32. Salloum RG, LeLaurin JH, Dallery J, Childs K, Huo J, Shenkman EA, et al. Cost evaluation of tobacco control interventions in clinical settings: a systematic review. Prev Med. 2021;146:106469. https://doi.org/10.1016/j.ypmed.2021.1 06469.

33. Slatore CG, Au DH, Hollingworth W. Cost-effectiveness of a smoking cessation program implemented at the time of surgery for lung cancer. J Thorac Oncol. 2009;4(4):499-504. https://doi.org/10.1097/JTO.0b013e3181 95e23a.

34. Emmons KM, Puleo E, Park E, Gritz ER, Butterfield RM, Weeks JC, et al. Peerdelivered smoking counseling for childhood cancer survivors increases rate of cessation: the partnership for health study. J Clin Oncol. 2005;23(27): 6516-23. https://doi.org/10.1200/JCO.2005.07.048.

35. Djalalov S, Masucci L, Isaranuwatchai W, Evans W, Peter A, Truscott R, et al. Economic evaluation of smoking cessation in Ontario's regional cancer programs. Cancer Med. 2018;7(9):4765-72. https://doi.org/10.1 002/cam4.1495

36. Parrott S, Godfrey C. Economics of smoking cessation. BMJ. 2004;328(7445): 947-9. https://doi.org/10.1136/bmj.328.7445.947.

37. Cromwell J, Bartosch WJ, Fiore MC, Hasselblad V, Baker T. Costeffectiveness of the clinical practice recommendations in the AHCPR guideline for smoking cessation. Agency for Health Care Policy and Research. JAMA. 1997;278(21):1759-66. https://doi.org/10.1001/jama.1997. 03550210057039.

38. Palinkas LA, Aarons GA, Horwitz S, Chamberlain P, Hurlburt M, Landsverk J. Mixed Method Designs in Implementation Research. Adm Policy Ment HIth. 2011;38(1):44-53. https://doi.org/10.1007/s10488-010-0314-z.

39. Saldana $\mathrm{L}$. The stages of implementation completion for evidence-based practice: protocol for a mixed methods study. Implementation Science. 2014;9(1):43. https://doi.org/10.1186/1748-5908-9-43.

40. Dopp AR, Mundey P, Beasley LO, Silovsky JF, Eisenberg D. Mixed-method approaches to strengthen economic evaluations in implementation research. Implementation Science. 2019;14(1):2. https://doi.org/10.1186/s13 012-018-0850-6.

41. Yin RK. Case Study Research Design and Methods. 4th ed. Thousand Oaks, CA: SAGE Publications, Inc:; 2009.

42. Onwuegbuzie AJ, Teddlie C. A framework for analyzing data in mixed methods research. Handbook Mixed Methods Soc Behav Res. 2003;2:397-430.

43. Husereau D, Drummond M, Petrou S, Carswell C, Moher D, Greenberg D, et al. Consolidated Health Economic Evaluation Reporting Standards (CHEERS) statement. BMJ. 2013;346(mar25 1):f1049. https://doi.org/10.1136/bmj.f1049.

44. Ritzwoller DP, Sukhanova A, Gaglio B, Glasgow RE. Costing behavioral interventions: a practical guide to enhance translation. Ann Behav Med. 2009;37(2):218-27. https://doi.org/10.1007/s12160-009-9088-5.

45. U.S. Bureau of Labor Statistics. Occupational Employment Statistics. 2020.

46. US Bureau of Labor Statistics. Consumer Price Index Calculator. [https://data. bls.gov/cgi-bin/cpicalc.pl]. Accessed 4 Dec 2020.

47. Damschroder LJ, Aron DC, Keith RE, Kirsh SR, Alexander JA, Lowery JC. Fostering implementation of health services research findings into practice: a consolidated framework for advancing implementation science. Implement Sci. 2009;4(1):50. https://doi.org/10.1186/1748-5908-4-50.

48. Warren GW, Marshall JR, Cummings KM, Toll BA, Gritz ER, Hutson A, et al. Addressing tobacco use in patients with cancer: a survey of American Society of Clinical Oncology members. J Oncol Pract. 2013;9(5):258-62. https://doi.org/10.1200/JOP.2013.001025.

49. Salloum RG, Lee J, Lee J-H, Boeckmann M, Xing C, Warren GW. Smoking cessation methods and outcomes among cancer survivors. Am J Prev Med. 2020;59(4):615-7. https://doi.org/10.1016/j.amepre.2020.03.016.

50. Wiseman KP, Hauser L, Clark C, Odumosu O, Dahl N, Peregoy J, Sheffield CW, Klesges RC, Anderson RT. An evaluation of the process and quality improvement measures of the University of Virginia cancer center tobacco treatment program. Int J Environ Res Public Health. 2020;17(13):4707.

51. Meyer C, Mitra S, Ruebush E, Sisler L, Wang K, Goldstein AO. A lean quality improvement initiative to enhance tobacco use treatment in a cancer hospital. Int J Environ Res Public Health. 2020;17(6):2165. 
52. Tong EK, Wolf T, Cooke DT, Fairman N, Chen MS. The Emergence of a sustainable tobacco treatment program across the cancer care continuum: a systems approach for implementation at the University of California Davis comprehensive cancer center. Int J Environ Res Public Health. 2020;17(9): 3241 .

53. Goldstein AO, Shoenbill KA, Jolly TA. Intensive smoking cessation counseling for patients with cancer. JAMA. 2020;324(14):1401-3. https://doi. org/10.1001/jama.2020.13102.

\section{Publisher's Note}

Springer Nature remains neutral with regard to jurisdictional claims in published maps and institutional affiliations.

- fast, convenient online submission

- thorough peer review by experienced researchers in your field

- rapid publication on acceptance

- support for research data, including large and complex data types

- gold Open Access which fosters wider collaboration and increased citations

- maximum visibility for your research: over $100 \mathrm{M}$ website views per year

At $\mathrm{BMC}$, research is always in progress. 